\title{
Utilization of Institutional Delivery Service and Associated Factors among Women of Child Bearing Age in Bule Hora Town, West Guji Zone, Oromia Regional State, Ethiopia. Community Based Cross- Sectional Study Design, 2018
}

Zelalem Jabessa Wayessa ( $\square$ zelalemjebessa@gmail.com ) https://orcid.org/0000-0003-3416-6810

\section{Udessa Gamede}

Bule Hora University

Research article

Keywords: Utilization, Institutional delivery, associated factors, child bearing women, Bule Hora town.

Posted Date: August 21st, 2019

DOI: https://doi.org/10.21203/rs.2.13301/v1

License: (c) (1) This work is licensed under a Creative Commons Attribution 4.0 International License. Read Full License 


\section{Abstract}

Background:-Globally at least 303,000 women died during pregnancy and childbirth and every day approximately 830 women die from preventable causes related to pregnancy and childbirth. Although institutional delivery has been promoted in Ethiopia, still delivery in a health facility is far lower than other neighboring countries. The aim of this study was to assess utilization of institutional delivery service and associated factors among women of childbearing age in Bule Hora town, West Guji zone, Oromia regional state, Ethiopia Methods: - Community-based cross-sectional study design with quantitative methods of data collection was employed from February 01 to March 30/2018. A total of 360 childbearing mothers in the Bule Hora town were involved in the study using a systematic sampling method. The instrument was pre-tested on $5 \%$ the sample at Gerba town. The data were analyzed by using binary and multivariable logistic regression and statistical associations were measured using odds ratio and $95 \% \mathrm{Cl}$. Results: - The prevalence of utilization of institutional delivery services in Bule hora town is $72 \%$. According to this finding age at first pregnancy (AOR: 2.08, 95\%Cl: 1.768-5.620), educational status of mothers who attended secondary school and above (AOR: $4.613,95 \% \mathrm{Cl}: 1.096-11.912$ ) and primary school attended mothers (AOR:3.18, 95\% Cl: 2.406-3.443), educational status of husbands who attended secondary school and above (AOR: $4.91,95 \% \mathrm{Cl}$ : 10.792-30.441)and primary school attended (AOR: 2.13, 95\%Cl: 8.35912.616), spousal communication about place of delivery (AOR: $4.27,95 \% \mathrm{Cl}: 1.823-10.004$ ), husbands occupations (AOR: 2.94, 95\% Cl: 2.734-5.137), current antenatal care (AOR: 46.74, 95\%Cl: 16.778-30.210), and parity three and less children (AOR: $6.97,95 \% \mathrm{Cl}: 1.305-37.212$ were had a strong statistical association with utilization of institutional delivery service. Conclusions: - The finding shows the utilization of institutional delivery service in Bule Hora town is higher than a national figure but lower than the national target of skilled delivery. Policymaker and health institutions should have to strength and create awareness of the community on the importance of institutional delivery and use of ANC service in order to screen and detect early signs of disease, followed by timely intervention.

\section{Background}

Globally in 2015, roughly 303,000 women died during pregnancy and childbirth and every day, approximately 830 women die from preventable causes related to pregnancy and childbirth(3). Maternal mortality is the global health indicator with the largest disparity between developed and developing countries. The survival, health and well- being of women's are essential to ending extreme poverty, promoting development, achieving the global strategy and sustainable development goals (9).

The average global target is to reduce maternal mortality to less than 70 per 100,000 live births and no country should have an MMR greater than 140/100 000 live births by 2030 and to reduce new born mortality to at least as low as 12 per 1,000 live births in every country (10). The estimated lifetime risk of maternal mortality in high-income countries is 1 in 3300 in comparison with 1 in 41 in low-income countries and in countries designated as fragile states, the estimated lifetime risk of maternal mortality is 1 in 54(11). 
Although widespread progress has been made in recent decades, in Africa 50 percent of women give birth without a skilled attendant and the average coverage of births with a skilled attendant on the continent has not increased significantly (12). Most maternal deaths occur during labor and delivery, or the first 24 hours postpartum, and most complications cannot be predicted or prevented. Nearly $75 \%$ of all maternal deaths on the continent are attributable to the complications of pregnancy and childbirth like severe bleeding, infections, high blood pressure during pregnancy and other complications from delivery and unsafe abortion. The remaining $25 \%$ are caused by associated with diseases such as malaria, and HIV/AIDS during pregnancy. Ethiopia is one of the highest maternal mortality ratios. In order to minimize this national target is to reduce to 199/100,000 (13), But in 2016 maternal mortality ratio was 412 deaths per 100,000 live births (1).

In Ethiopia twenty-six percent of live births were delivered in a health facility that is far lower than in other neighboring African countries, such as Egypt $87 \%$ in 2014, Eritrea 34\% in 2010, Djibouti $87 \%$ in 2012, Kenya $61 \%$ in 2014, Sudan 28\% in 2014 and Somalia 9\% in 2006 were delivered in a health facility. Institutional deliveries for women living in rural areas of Ethiopia has substantially increased in the last 16 years, from $2 \%$ in 2000 to $20 \%$ in the 2016 EDHS and among urban women has also increased from $32 \%$ in 2000 to $79 \%$ in 2016 . The national target of skilled delivery is $90 \%$ (13) but the achievements were $28 \%$ of births delivered by a skilled provider. The majority of births are attended by traditional birth attendant $(42 \%)$, nurses or midwives $(20 \%)$ followed by doctors $(6 \%)$, health extension workers $(2 \%)$, and health officers $(0.4 \%)(1,14)$.

Institutional delivery service utilization and deliveries attended by skilled provider in Oromia were 19 and 20 percent respectively, which are far less than 57 and 59 percent institutional delivery and deliveries attended by skilled providers in Tigray region (1). In order to achieve global strategies and sustainable development goal it needs to identify facilitators and barriers of institutional delivery (13).

Therefore, this community based cross-sectional study was conducted to determine the magnitude of institutional delivery and factors determining place of deliveries and proposed to fill this information gap in west Guji zone with the potential of generalizability of its result to similar settings (Figure 1).

\section{Methods}

The study was conducted from February 01 to March 30/2018 in western Guji zone in Oromia Region, Ethiopia. It is found $467 \mathrm{Km}$ a long way from Addis Ababa toward the south direction at $5^{\circ} 35^{\prime} \mathrm{N}$ Latitude and $38^{\circ} 15^{\prime} \mathrm{E}$ Longitude. A Community based cross-sectional study design with quantitative techniques for information gathering was utilized. The source populations were all women of childbearing age who gave birth over the most recent two years preceding the time of data collection in Bule Hora town. Inclusion criteria were women who gave birth in the last two years and resident in the area for at least 6 months available during data collection period were included and women who gave birth in other places but living in the study area at the time of data collection and critically ill, cannot talk or listen were excluded. 
The determined sample size was 360 childbearing women by utilizing single population proportion, considering the prevalence of institutional delivery service utilization $57 \%$ (25), a margin of error $5 \%$, $95 \%$ confidence interval, $10 \%$ non-response rate, and correction formula were utilized. Systematic sampling methods were applied. First, an enumeration was conducted in the kebeles to distinguish women who gave birth within the previous 2 years in Bule Hora town and lived at least a half year in the town before the investigation. Bule Hora town has three kebeles and all kebeles were incorporated into the study and in each kebeles, the households having the eligible women were distinguished by the house to house. The eligible women in kebele ones, kebele two and kebele three were 602, 867, and 913 independently. After eligible women were identified, the sampling frame was prepared. The proportional probability to size sampling technique was used to allocate proportional sample size for each kebeles. Then systematic sampling technique was used after determining the interval by dividing the number of all women who gave birth in the last two years in Bule Hora town to final sample size. Every seventh who are voluntary to participate were interviewed according to their sequence of house numbers. Whenever two or more eligible women were found in the same household only one of them was selected randomly and included in the study (Figure 2).

Data were gathered using an organized questionnaire which intended to cover all contents of sociodemographic, socio-economic, socio-cultural, obstetric factors and perceived quality of health care factors variables to accomplish the goal of this study. The quality of the data was assured by using validated pre-tested questionnaires and questionaries' were translated into Afaan Oromo. Data collectors were prepared for one day seriously on the investigation instrument and data collection procedure that includes the relevance of the study, the objective of the study, confidentiality of the information, informed consent and interview technique. The data collectors were worked under the nearby supervision of the supervisors to guarantee adherence to address data collection procedures and the supervisors and investigators review the filled questionnaires at the end of data collection every day for completeness.

Data were cleaned, coded, checked for completeness and inconsistencies and entered into Epi-Data Version 3.1 and exported to SPSS Statistics Version 25 for analysis. Percentage, frequency and mean were determined. Binary logistic regression analysis independent variables significant at $p<0.25$ was considered for adjustment in the multivariable logistic regression. By multivariable logistic regression analysis, the strength of statistical association was measured by adjusted odds ratios and $95 \%$ confidence intervals and statistical significance was declared at $P<0.05$. Finally, the result was presented using texts, tables, figures and charts.

\section{Results}

Results: - Out of 360 sample size, 357 participants were engaged in the study with a $99 \%$ response rate and the most regular respondents' age groups were $20-24$ age groups which account for $147(41.2 \%)$. The mean age of the respondent was 24.44 years (Standard Deviation, SD $=4.95$ ). The age of the respondents ranges from 15 to 40 years. Three hundred fifty (98\%) of the women were married. The dominant parts of the respondents were Protestant by religion $289(81 \%)$ and Oromo by ethnic gathering 
324(90.8\%) (Table 1). Right around 337 (85.7\%) of the women had attended formal education. The mean month to month pay of respondents was 2452.58 Ethiopian birrs (Table2). The mean age of respondents' first pregnancy was 17.62 years with standard deviations of +1.7 years and the mean period of the respondent of last pregnancy 23.11 years with a standard deviation of +4.78 years (Table 3 ).

The investigation demonstrated most of the respondents, 281(78.7\%) visit antenatal care and out of those mothers $119(42 \%)$ visit the health facility at three months, $56(19.8 \%)$ at one month, $52(18.4 \%)$ at two months, 32(11.3\%) at four-month, 20(7.1\%) at five months and the rest were attended antenatal care after five months of gestational age. With respect to the number of antenatal care visit out of antenatal care followers $104(38.2 \%)$ visit four times,56(19.8\%) visit three times,52(18.4\%) visit six times, 44 (15.5\%) visit five times, $9(3.2 \%)$ visit two times and the rest where visited more than six times. During antenatal care visit, 279(98.6\%) receive any information and advice about the place to give birth and related complication during labor and delivery. Out of $279(98.8)$ respondents receive information about complication during labor and delivery, 98(35.3\%) severe vaginal bleeding, 49(17.6\%) prolonged labour, $43(15.5 \%)$ severe headache, $37(13.3 \%)$ cessation of fetal movement, $26(9.4 \%)$ markedly weight gain of mothers and $25(9 \%)$ retained placenta. The reasons given by the mother didn't go to antenatal care visits are there were no medical issue workload, terrified of the expense, Poor treatment of well-being specialist and feel disgrace (Figure3).

\section{Utilization of institutional delivery service}

The greater part (72\%) of the mothers gave birth at the health facility and the rest of them gave birth at home (Figure 4 and 5). The reason given by mothers those gave birth at homes were:- it is their usual experience, had short labor, had a bad experience from past health facility delivery, felt more comfortable when giving birth at home and their family gives close attention.

\section{Factors associated with Utilization's of institutional delivery service among Independent predictor variables}

The binary logistic regression analysis was performed to identify variables candidate for multivariable logistic regression analysis with the utilization of institutional delivery services. Consequently, maternal age, educational status of mothers, educational status of husbands, spousal communication, decisionmaker on place of delivery, mothers occupations, husbands occupations, current antenatal care, family size, parity, competence of skill attendants, shortage of skilled attendants in health facility, prefer of sex of care provider during labor/delivery are variables candidate for multiple logistic regression, since their $\mathrm{p}$ values were less than 0.25 (Tables 4 ).

In this study multivariable logistic regression analysis was performed to identify factors which had a strong association with utilization of institutional delivery service (Table 5).

According to this finding age at first pregnancy, educational status of mothers, educational status of husbands, spousal communication, husbands occupations, current antenatal care, and parity were had a 
strong statistical association with utilization of institutional delivery service.

A multivariable logistic regression analysis shows as age at first pregnancy greater than 18 years were 2.077 (1.768-5.620) times more likely to give birth at a health facility than those who became pregnant before 18 years of age. Mothers' education was very important factors determine the place of delivery, thus mothers attended secondary school and above were 4.613(1.096-11.912) times and primary school attended mothers were $3.183(2.406-3.443)$ times more likely to give birth at a health facility than illiterate mothers.

Husband education had also a statically significant association with utilization of institutional delivery service. A wife whose husbands' attended secondary school and above were 4.911(10.792-30.441) times and primary school attended $2.129(8.359-12.616)$ time more likely to give birth at a health facility compared with illiterate husbands. According to this finding spousal communication on the place of delivery also had a positive association with institutional delivery services. Spousal communication on the place of delivery was $4.270(1.823-10.004)$ times more likely to utilize institutional delivery service compared with no communication in the place of delivery. Mothers who had currently attended antenatal care were $46.740(16.778-30.210)$ more likely to utilize institutional delivery services than others.

The study finds out occupations of a husband had a statistically significant association with utilization of institutional delivery services. Mothers whose husbands' the government employs 2.942 (2.734-5.137) times more likely to give birth at a health facility compared with private employ. Another strong factor for the utilization of health care for delivery is parity. Mothers who gave birth three times and less $(<=3)$ and four to six(4-6) were 6.969(1.305-37.212) and 4.449(2.787-25.138) times more likely to give birth at health facility respectively as compared with mothers who gave birth seven times and more.

\section{Discussion}

This study assessed the utilization of institutional delivery service and associated factors among women of childbearing age who delivered two years preceding to the survey in Bule Hora town, West Guji Zone, Oromia regional state, Ethiopia. The study shows that the prevalence of the utilization of institutional delivery services in Bule Hora town is $72 \%$. This finding was higher than the previous study conducted in Dodota Ethiopia (18\%), Benishangul Ethiopia (24.8\%), Gurage zone Ethiopia (31\%), Sodo town Ethiopia (62.2\%), Boricha southern Ethiopia (4.9\%), Horro Guduru Wollega Ethiopia (57\%), Awi zone Amhara Ethiopia (18.8\%), Abuna Gindebret Ethiopia (14.4), Bihar Amulo Tanzania (56\%) respectively gave birth at a health facility $(16,17,19,22,24,25,26,31,21)$. It is also high compared to the national average $(26 \%)$ in Ethiopia of 2015. Additional efforts are needed to ensure that the Ethiopia national target of $90 \%$ is achieved (13). The difference between this study and others may be due to the residence of respondents, level of awareness of mothers about importance institutional delivery services and currently Ethiopian ministry of health using different strategies to increase institutional delivery services like free delivery services at all health facility. 
This finding is consistent with a study done in the Gamo Gofa zone in which $73.2 \%$ of women gave birth in health institutions (20). However, a study conducted in Bahir Dar city administration (78.8\%), Benchi Maji (78.3\%) and Debra Berhan (80.2\%) were higher than our finding. The possible justification might be the infrastructure and the cultural differences that might exist across these regions. In this study, factors influencing institutional delivery services were the age at first pregnancy, educational status of mothers, educational status of husbands, spousal communication, husband's occupations, current antenatal care and parity of women.

According to this study, age at first pregnancy was important variables predictors of institutional delivery services. This study in line with the finding in Benishangul (17) and Bahir Dar city administration (18). In case of this study as an age of mothers increase from eighteen and above the possibility to give birth at health facility increase, the possible reason might be as their age increase they will get more information about the importance of giving birth at a health facility. The educational status of the mother is also a positive statistically significant association with institutional delivery services. The finding is consistent with studies done in Dodota Ethiopia (16), Bahir Dar Ethiopia (18), Tanzania (21), Sodo town Ethiopia (23), Boricha Ethiopia (24), Benchi Maji Ethiopia (26) and Debra Berhan (32). This might be women who are educated might have access to information, better knowledge on services, access and control over resources and thus might better use health facility for delivery and education helps to understand about the danger signs and complications during pregnancy and delivery.

Parity is another variable strongly determine the utilization of institutional delivery services. Mothers who gave birth three times and less were 6.97 times and who gave birth four to six were 4.45 times more likely to give birth at health facility respectively compared with mothers whose gave birth seven times and more. A similar study in line with this finding done in Sodo town Ethiopia (22). The justification might be due to the expansion of the health extension worker program and education in the last two decade in Ethiopia. This indicates mothers those gave birth more than seven times were using their experience at home birth and less utilize institutional delivery service.

Our study also revealed that the educational status of husbands increases institutional delivery service of mothers compared with uneducated husbands. Similar studies in line with this finding sodo town Ethiopia and reviewed web-based search study $(22,30)$. A possible reason for this finding is decision making about a place of delivery 242(67.8\%) were decided by both husband and wife, $94(26.3 \%)$ were decided by herself, 11(3.1\%) were decided by their husbands. This is shows educated husbands were influenced their family on the choice of place of delivery. Women who had spousal communication on the place of delivery were four times more likely to utilize institutional delivery service compared with women who had no communication in the place of delivery.

In this study, antenatal care was determinant factors of institutional delivery service, which increase the utilization of institutional delivery services. This finding is consistent with different studies in Benishangul Ethiopia (17), Bahir Dar Ethiopia (18), Sodo town Ethiopia (22, 23), Boricha Ethiopia (24), Horro Guduru Wollega (25), Awi zone Amhara Ethiopia (27), Abuna Gindebret Ethiopia (31) and Debra 
Berhan (32). Majority of mothers those attended antenatal care gave birth at a health facility. This is due to awareness creation on the importance of institutional delivery service and related complications of pregnancy and delivery during antenatal care.

\section{Conclusion}

The finding shows the utilization of institutional delivery service is higher than a national figure but lower than the national target. Since all study participants were from urban, the finding was higher than a national figure and other studies in a country. Age at first pregnancy, educational status of mothers, educational status of the husband, current antenatal care visit, parity, spousal communication in place of delivery and husband occupation were had a positive statistically significant association with institutional delivery services.

\section{List Of Abbreviations}

ANC:-Ante Natal Care, AIDS: - Acquired Immune Deficiency Syndrome, EDHS: - Ethiopian Demographic Health Survey, FGD: - Focus Group Discussion, HIV: - Human Immunodeficiency Virus, IRB: - Institutional Review Board, MMR:-Maternal Mortality Ratio, SAD: - Skilled Assisted Delivery and TBA: - Traditional Birth Attendants

\section{Declarations}

\section{Acknowledgements}

We are thankful to all our department technical staffs for their excellent technical support. We are grateful to all the participants for their cooperation and Bule Hora University for financial support.

\section{Funding}

Bule Hora University fund this research to solve community problems.

\section{Availability of data and materials}

The datasets used and/or analysed during the current study are available from the corresponding author on reasonable request.

\section{Author's Contributions}

ZJ have made substantial contributions to beginning and design, collection of data, analysis and interpretation of data and develop this manuscript.

UG have also made substantial contributions to beginning and design, collection of data, analysis and interpretation of data and develop this manuscript. 
Both author and co-author read and approved the final manuscript

\section{Ethics approval and consent to participate}

Ethical clearance was obtained from Bule Bora University IRB with reference number, Ref.No (BHU/PRD/157/2010 E.C/2018) and written consent were obtained from all respondents. To get full cooperation, respondents were reassured about the confidentiality of their response. Their voluntary participation and the right to take part or terminate at any time they wanted were assured. The data collectors were trained by the principal investigators on how to keep the confidentiality and anonymity of the responses of the respondents in all aspect.

\section{Consent for publication}

Not applicable

\section{Competing interests}

The authors declare that they have no competing interests.

\section{Author details}

\section{Zelalem Jabessa (BSc.N, MSc.N) ${ }^{1 *}$}

Departement of Nursing and Midwifery, College of Health and medical Sciences, Bule Hora University, PO.Box:144, Bule Hora, Ethiopia

zelalemjebessa@gmail.com (corresponding Author)

2. Uddessa Gamede (BSc.N) ${ }^{1}$

Departement of Nursing and Midwifery, College of Health and medical Sciences, Bule Hora University, PO.Box:144, Bule Hora, Ethiopia

yooyyaa123@yahoo.com (Co-Author)

\section{References}

1. Central Statistical Agency (CSA) [Ethiopia] and ICF. Ethiopia Demographic and Health Survey 2016: Key Indicators Report. Addis Ababa, Ethiopia, and Rockville, Maryland, USA. CSA and ICF; 2016.

2. International Statistical classification of diseases and related health problems. WHO. September 2015.

3. CSIS Global Health Policy Center. Maternal and Child Health. October 2016, P3.

4. GSS, GHS, ICF International. Ghana demographic and health survey 2014. Accra, Ghana: Ghana Statistical Service, Ghana Health Service, and ICF International. 2015 
5. UNICEF/For Every Children. Maternal and New-born Health Disparities in Ethiopia, Key facts, 2015

6. World Health Organization. Maternal mortality. Fact sheet No348. WHO. 2015.

7. Maternal Mortality: Saving Women's Lives Globally. visit: http://www.cdc.gov/ global health/health protection/ncd, 2016

8. Ministry of Health. "HSDP IV Annual Performance Report". FMOH. 2015

9. The Global Strategy For Women's, Children's And Adolescents' Health (2016-2030), survive strive transformation, every women every children, 2015.

10. World Health Organization. Strategies toward ending preventable maternal mortality (EPMM) 2015

11. WHO, UNICEF, UNFPA, World Bank Group and UNPD estimates. Trends in Maternal Mortality:1990 to 2015

12. Federal Democratic Republic of Ethiopia Ministry of Health. Training Manual, Basic Emergency Obstetric \& Newborn Care (BEmONC), 2013.

13. FDRE Ministry of Health. Health Sector Transformation Plan. 2015/16 - 2019/20

14. Joint UNICEF/WHO database. Skilled attendant at delivery. SDG indicator 3.1.2, Update: February 2017.

15. Iffat J. etal. Role of partogram in preventing prolonged labour. Jinnah Postgraduate Medical Center, Karachi. 2007. 408-410.

16. Fikre and Demissie: Prevalence of institutional delivery and associated factors in Dodota Woreda (district), Oromia regional state, Ethiopia. Reproductive Health 2012 9:33

17. Muluwas A. Muluemebet A \&Misra A. Utilization of Institutional Delivery Care Services and Influencing Factors among Women of Child Bearing Age in Assosa District, BenishangulGumuz Regional State, West Ethiopia. Global Journals Inc. (USA), Volume 16 Issue 3 Version 1.0 Year 2016.

18. Abeje et al.: Factors associated with Institutional delivery service utilization among mothers in Bahir Dar City administration, Amhara region: a community based cross sectional study. Reproductive Health 2014 11:22

19. Feleke $\mathrm{H}$ and Meaza D. Magnitude and factors associated with institutional delivery service utilization among childbearing mothers in Cheha district, Gurage zone, SNNPR, Ethiopia: a community based cross sectional study. BMC Pregnancy and Childbirth (2015) 15:299.

20. Woiynshet $\mathrm{G}$ et al.: Assessment of Factors Affecting Institutional Delivery Service Utilization Among Mother Who Gave Birth in Last Two Years, Arbaminch Town, GamoGofa Zone, Snnpr, Ethiopia. Science Journal of Public Health 2016; 4(6): 458-462.

21. Kihulya M. \&, Elia J. Prevalence and predictors of institutional delivery among pregnant mothers in Biharamulo district, Tanzania: a cross-sectional study. Pan African medical journals, 2015; 21:51 doi:10.11604/pamj.2015.21.51.6347.

22. Hailemichael F, Woldie M, Tafese F. Predictors of institutional delivery in Sodo town, Southern Ethiopia. Afr J Prm Health Care Fam Med. 2013; 5(1), Art. \#544, 9 pages. htp://dx.doi.org/10.4102/phcfm.v5i1.544 
23. Hagos et al.: Utilization of institutional delivery service at Wukro and Butajera districts in the Northern and South Central Ethiopia. BMC Pregnancy and Childbirth 2014 14:178.

24. Tafese T, Alemu T and Tariku T. Factors Associated with Institutional Delivery in Boricha District of Sidama Zone, Southern Ethiopia. International Journal of Public Health Science (IJPHS), Vol.3, No.4, December 2014, pp. $224 \sim 230$

25. Demisew B. and Adamu B. Point Prevalence and Factors Associated with Institutional Delivery among Married Women in Reproductive Age in Abe, Dongoro Woreda, Horro Guduru Wollega Zone, Oromia Region, Western Ethiopia.Journal of Pharmacy and Alternative Medicine, Vol.13, 2016.

26. Fira A. and Tariku T. Delivery Site Preferences and Associated Factors among Married Women of Child Bearing Age in Bench Maji Zone, Ethiopia.Ethiop J Health Sci. Vol. 26, No. 1 January 2016.

27. Mulunesh $A$ and Wubegzier M.The Prevalence of Skilled Birth Attendant Utilization and Its Correlates in North West Ethiopia.Biomed Research International Volume 2015, Article ID 436938, 8 page.

28. Yibeltal T., Yohana J. and Gloria T. Factors Influencing Women's Preferences for Places to Give Birth in Addis Ababa, Ethiopia. Obstetrics and Gynecology International Volume 2015, Article ID 439748, 7 pages.

29. Niguse T. and Tafesse L. Utilization of institutional delivery service and associated factors in Bench Maji zone, Southwest Ethiopia: community based, cross sectional study. BMC Health Services Research (2017) 17:101

30. Alemi K., Kalkidan $\mathrm{H}$, and Aderajew N. Factors associated with institutional delivery service utilization in Ethiopia. International Journal of Women's Health, September 2016.

31. Birhanu D., Nagasa D., Fikru T and at el. Institutional delivery and postnatal care services utilizations in AbunaGindeberet District, West Shewa, Oromia Region, Central Ethiopia: A Community-based cross sectional study.BMC Pregnancy and Childbirth (2016) 16:149

32. Limenih A, Deyesa N, Berhane A (2016) Assessing the Magnitude of Institutional Delivery Service Utilization and Associated Factors among Mothers in Debre Berhan, Ethiopia. J Preg Child Health 3: 254. doi:10.4172/2376-127X.1000254

\section{Tables}

Table 1 distributions of socio-demographic characteristics of women of childbearing age in Bule Hora town, West Guji Zone, Oromia regional state, Ethiopia, 2018 


\begin{tabular}{|c|c|c|c|}
\hline Variables & & Frequency & Percent \\
\hline \multirow[t]{5}{*}{ Maternal age } & $<=19$ & 52 & 14.6 \\
\hline & $20-24$ & 147 & 41.2 \\
\hline & $25-29$ & 92 & 25.8 \\
\hline & $30-34$ & 46 & 12.9 \\
\hline & $>=35$ & 20 & 5.6 \\
\hline \multirow[t]{3}{*}{ Marital status } & Married & 350 & 98.0 \\
\hline & Widowed & 5 & 1.4 \\
\hline & Divorced & 2 & .6 \\
\hline \multirow[t]{5}{*}{ Ethnicity } & Oromo & 324 & 90.8 \\
\hline & Amhara & 12 & 3.4 \\
\hline & Gedeo & 12 & 3.4 \\
\hline & Burji & 3 & .8 \\
\hline & Walayita & 6 & 1.7 \\
\hline \multirow[t]{5}{*}{ Religion } & Protestant & 289 & 81.0 \\
\hline & Orthodox & 34 & 9.5 \\
\hline & Muslim & 28 & 7.8 \\
\hline & Catholic & 4 & 1.1 \\
\hline & Wakefata & 2 & .6 \\
\hline \multirow[t]{3}{*}{ Family size } & $<=3$ & 92 & 25.8 \\
\hline & $4-6$ & 192 & 53.8 \\
\hline & $>=7$ & 73 & 20.4 \\
\hline
\end{tabular}

Table 2 distributions of socio-economic characteristics of women of childbearing age in Bule Hora town, West Guji Zone, Oromia regional state, Ethiopia, 2018 


\begin{tabular}{|c|c|c|c|}
\hline \multicolumn{2}{|l|}{ Variables } & frequency & percent \\
\hline \multirow[t]{4}{*}{ Educational status of mothers } & Illiterate & 79 & 22.1 \\
\hline & Can read and write & 21 & 5.9 \\
\hline & primary education & 79 & 22.1 \\
\hline & secondary school and above & 178 & 49.9 \\
\hline \multirow[t]{4}{*}{ Occupations of mothers } & government employ & 67 & 18.8 \\
\hline & Housewife & 236 & 66.1 \\
\hline & private/merchant & 53 & 14.8 \\
\hline & Others & 1 & .3 \\
\hline \multirow[t]{4}{*}{ Educational status of husbands } & Illiterate & 19 & 5.3 \\
\hline & Can read and write & 27 & 7.6 \\
\hline & primary education & 70 & 19.6 \\
\hline & secondary school and above & 241 & 67.5 \\
\hline \multirow[t]{4}{*}{ Occupation of husbands } & government employ & 174 & 48.7 \\
\hline & Farmer & 72 & 20.2 \\
\hline & private/merchant & 106 & 29.7 \\
\hline & Student & 5 & 1.4 \\
\hline \multirow[t]{5}{*}{ Monthly income } & $<=500$ & 9 & 2.5 \\
\hline & $501-1500$ & 67 & 18.8 \\
\hline & $1501-2500$ & 71 & 19.9 \\
\hline & $2501-3500$ & 57 & 16.0 \\
\hline & $3501-4500$ & 48 & 13.4 \\
\hline
\end{tabular}

Table 3 distributions of obstetrics factors of women of childbearing age in Bule Hora town, West Guji Zone, Oromia regional state, Ethiopia, 2018. 


\begin{tabular}{|l|l|r|r|}
\hline \multicolumn{2}{|l|}{ Variables } & frequency & percent \\
\hline Age at first pregnancy & $<=19$ & 326 & 91.3 \\
\cline { 2 - 4 } & $20-24$ & 28 & 7.8 \\
\cline { 2 - 4 } & $25-29$ & 3 & .8 \\
\hline Age at last pregnancy & $<=19$ & 99 & 27.7 \\
\cline { 2 - 4 } & $20-24$ & 134 & 37.5 \\
\cline { 2 - 4 } & $25-29$ & 89 & 24.9 \\
\cline { 2 - 4 } & $30-34$ & 28 & 7.8 \\
\cline { 2 - 4 } & $>=35$ & 7 & 2.0 \\
\hline Gravida & $<=4$ & 283 & 79.3 \\
\cline { 2 - 4 } & $5-8$ & 65 & 18.2 \\
\cline { 2 - 4 } & $>=9$ & 9 & 2.5 \\
\hline Parity & $>=3$ & 244 & 68.3 \\
\cline { 2 - 4 } & $4-6$ & 88 & 24.6 \\
\cline { 2 - 4 } & $>=7$ & 25 & 7.0 \\
\hline Recent ANC & No & 76 & 21.3 \\
\cline { 2 - 4 } & Yes & 281 & 78.7 \\
\hline History of Abortion & No & 318 & 89.1 \\
\cline { 2 - 4 } & Yes & 39 & 10.9 \\
\hline
\end{tabular}

Table 4: Shows the binary logistic regression analysis between the Utilization's of institutional delivery service and Independent variables among women of childbearing age in Bule Hora town, Oromia regional state, Ethiopia, 2018. 


\begin{tabular}{|c|c|c|c|c|c|c|}
\hline \multirow{2}{*}{\multicolumn{2}{|c|}{ Categorical variables }} & \multirow{3}{*}{$\frac{\mathbf{N}}{52}$} & \multirow{3}{*}{$\begin{array}{l}\mathbf{p} \\
.132\end{array}$} & \multirow{3}{*}{$\frac{\text { COR }}{2.250}$} & \multicolumn{2}{|c|}{ 95\% C.I. } \\
\hline & & & & & \multirow{2}{*}{$\begin{array}{c}\text { Lower } \\
.783\end{array}$} & \multirow{2}{*}{$\begin{array}{c}\text { Upper } \\
6.468\end{array}$} \\
\hline Maternal Age & $<=19$ & & & & & \\
\hline & $20-34$ & 285 & .025 & 2.851 & 1.141 & 7.124 \\
\hline & $>=35$ & 20 & & 1 & & \\
\hline \multirow{4}{*}{$\begin{array}{l}\text { Educational status of } \\
\text { mothers }\end{array}$} & Illiterate & 79 & & 1 & & \\
\hline & Can read and write & 21 & .992 & 1.005 & .373 & 2.708 \\
\hline & primary education & 79 & .000 & 3.329 & 1.733 & 6.398 \\
\hline & $\begin{array}{l}\text { secondary school } \\
\text { and above }\end{array}$ & 178 & .000 & 22.594 & 10.765 & 47.424 \\
\hline \multirow{4}{*}{$\begin{array}{l}\text { Educational status of } \\
\text { husbands }\end{array}$} & Illiterate & 19 & & 1 & & \\
\hline & Can read and write & 27 & .416 & 1.867 & .415 & 8.398 \\
\hline & primary education & 70 & .008 & 5.980 & 1.598 & 22.371 \\
\hline & $\begin{array}{l}\text { secondary school } \\
\text { and above }\end{array}$ & 241 & .000 & 36.129 & 9.950 & 131.182 \\
\hline \multirow[t]{2}{*}{ Spousal communication } & No & 110 & & 1 & & \\
\hline & Yes & 247 & .000 & 4.489 & 2.739 & 7.357 \\
\hline \multirow{4}{*}{$\begin{array}{l}\text { Decision maker on the } \\
\text { place of delivery }\end{array}$} & my self & 94 & & 1 & & \\
\hline & my husband & 11 & .002 & 26.154 & 3.188 & 214.587 \\
\hline & both of us & 242 & .000 & 19.210 & 10.589 & 34.848 \\
\hline & my relatives & 10 & .004 & 10.462 & 2.083 & 52.549 \\
\hline \multirow[t]{3}{*}{ Mothers occupations } & Government employ & 67 & .000 & 8.550 & 2.695 & 27.129 \\
\hline & House wife & 236 & .719 & 1.121 & .602 & 2.086 \\
\hline & private employ & 54 & & 1 & & \\
\hline \multirow[t]{3}{*}{ Husbands occupations } & $\begin{array}{l}\text { Governmental } \\
\text { employ }\end{array}$ & 174 & .000 & 5.275 & 2.836 & 9.813 \\
\hline & Farmer & 72 & .019 & .487 & .267 & .890 \\
\hline & private employ & 111 & & 1 & & \\
\hline \multirow[t]{2}{*}{ Current ANC } & No & 76 & & 1 & & \\
\hline & Yes & 281 & .000 & 66.141 & 29.135 & 150.149 \\
\hline \multirow[t]{3}{*}{ Family size } & $<=3$ & 92 & .000 & 3.455 & 1.779 & 6.708 \\
\hline & $4-6$ & 192 & .000 & 4.126 & 2.318 & 7.342 \\
\hline & $>=7$ & 73 & & 1 & & \\
\hline \multirow[t]{3}{*}{ Parity } & $<=3$ & 244 & .000 & 14.769 & 5.290 & 41.236 \\
\hline & $4-6$ & 88 & .000 & 8.571 & 2.917 & 25.184 \\
\hline & $>=7$ & 25 & & 1 & & \\
\hline \multirow{2}{*}{$\begin{array}{l}\text { Competence of skill } \\
\text { attendants }\end{array}$} & Not competent & 17 & & 1 & & \\
\hline & Competent & 241 & .013 & 10.578 & 1.641 & 68.202 \\
\hline
\end{tabular}




\begin{tabular}{|l|l|c|c|c|c|c|} 
& I don't know & 99 & .000 & .006 & .001 & .033 \\
\hline \multirow{2}{*}{$\begin{array}{l}\text { shortage of skilled } \\
\text { attendants in a health } \\
\text { facility }\end{array}$} & $\begin{array}{l}\text { There is a shortage } \\
\text { of care providers }\end{array}$ & 21 & & 1 & & \\
\cline { 2 - 7 } & $\begin{array}{l}\text { There is no shortage } \\
\text { of care providers }\end{array}$ & 237 & .044 & 6.132 & 1.054 & 35.661 \\
\cline { 2 - 7 } & I don't know & 99 & .000 & .006 & .001 & .031 \\
\hline \multirow{2}{*}{$\begin{array}{l}\text { Prefer of the sex of care } \\
\text { provider during labor }\end{array}$} & Female & 146 & & 1 & & \\
\cline { 2 - 8 } & Male & 19 & .008 & 15.692 & 2.041 & 120.654 \\
\cline { 2 - 7 } & Either of them & 192 & .000 & 4.528 & 2.737 & 7.491 \\
\hline \multirow{2}{*}{ Age at first pregnancy } & Age < 18 years & 167 & & 1 & & \\
\cline { 2 - 7 } & Age $>=18$ years & 190 & .000 & 2.362 & 1.470 & 3.795 \\
\hline
\end{tabular}

Tables:5 - Shows the multiple variable logistic regression and corresponding p-values for the associations between the Utilization's of institutional delivery service and independent variables among women of childbearing age in Bule Hora town, West Guji Zone, Oromia regional state, Ethiopia, 2018. 


\begin{tabular}{|c|c|c|c|c|c|c|}
\hline \multirow{2}{*}{\multicolumn{2}{|c|}{ Categorical variables }} & \multirow{3}{*}{$\frac{(\mathbf{N})}{79}$} & \multirow[b]{2}{*}{$\mathbf{P}$} & \multirow[b]{2}{*}{ AOR } & \multicolumn{2}{|c|}{ 95\% C.I. } \\
\hline & & & & & \multirow[t]{2}{*}{ Lower } & \multirow[t]{2}{*}{ Upper } \\
\hline \multirow{4}{*}{$\begin{array}{l}\text { Educational status of } \\
\text { mothers }\end{array}$} & Illiterate & & & 1 & & \\
\hline & Can read and write & 21 & .985 & 1.015 & .234 & 4.391 \\
\hline & primary education & 79 & .012 & 3.183 & 2.406 & 3.443 \\
\hline & $\begin{array}{l}\text { secondary school and } \\
\text { above }\end{array}$ & 178 & .005 & 4.613 & 1.096 & 11.912 \\
\hline \multirow{4}{*}{$\begin{array}{l}\text { Educational status of } \\
\text { husbands }\end{array}$} & Illiterate & 19 & & 1 & & \\
\hline & Can read and write & 27 & .927 & 1.106 & .126 & 9.727 \\
\hline & primary education & 70 & .015 & 2.129 & 8.359 & 12.616 \\
\hline & $\begin{array}{l}\text { secondary school and } \\
\text { above }\end{array}$ & 241 & .007 & 4.911 & 10.792 & 30.441 \\
\hline \multirow[t]{2}{*}{ Spousal communication } & No & 110 & & 1 & & \\
\hline & Yes & 247 & .001 & 4.270 & 1.823 & 10.004 \\
\hline \multirow[t]{3}{*}{ Husbands occupations } & Governmental employ & 174 & .001 & 2.942 & 2.734 & 5.137 \\
\hline & Farmer & 72 & .133 & 1.732 & 0.596 & 5.037 \\
\hline & private employ & 111 & & 1 & & \\
\hline \multirow[t]{2}{*}{ Current ANC } & No & 76 & & 1 & & \\
\hline & Yes & 281 & .000 & 46.740 & 16.778 & 30.210 \\
\hline \multirow[t]{3}{*}{ Parity } & $<=3$ & 244 & .023 & 6.969 & 1.305 & 37.212 \\
\hline & \begin{tabular}{|l|}
$4-6$ \\
\end{tabular} & 88 & .041 & 4.449 & 2.787 & 25.138 \\
\hline & $>=7$ & 25 & & 1 & & \\
\hline \multirow{2}{*}{$\begin{array}{l}\text { Age at first } \\
\text { pregnancy }\end{array}$} & $<18$ years & 167 & & 1 & & \\
\hline & $>=18$ years & 190 & .010 & 2.077 & 1.768 & 5.620 \\
\hline
\end{tabular}

\section{Figures}




\section{Socio-Demographic Factors}

1. Age

2. Ethnicity

3. Marital status

4. Family size

Socio-Cultural Factors

- Religion

- Preference of place of delivery

- Preference of sex of health care provider

- Decision making power

- Spousal communication

Socio-Economic Factors

- Occupation of mothers

- Income of mothers

- Educational level of mothers

- Occupation of husbands

- Educational level of husbands

\section{Obstetrics Factors}

5. Age at first pregnancy

6. Age at last pregnancy

7. gravidity

8. Parity

9. History of abortion

10. Use of ANC

11. History of recent delivery

Perceived quality of healthcare related factors

- Privacy

- Perceived shortage of skilled attendants

- Perceived incompetent skilled attendants

\section{Figure 1}

The schematic representation of the conceptual frame developed after reviewing different literature by authors. 


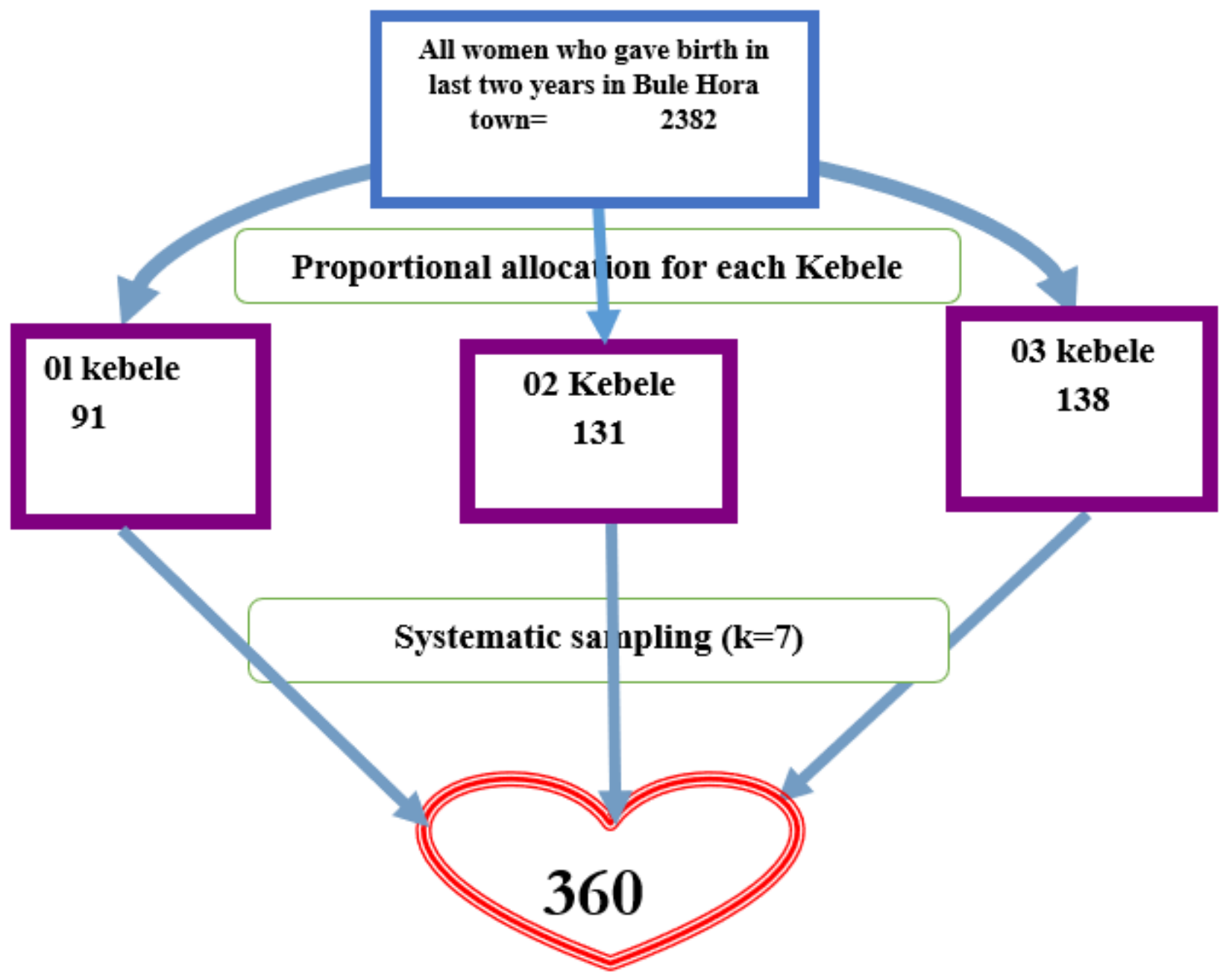

Figure 2

The schematic representation of the sampling procedures 


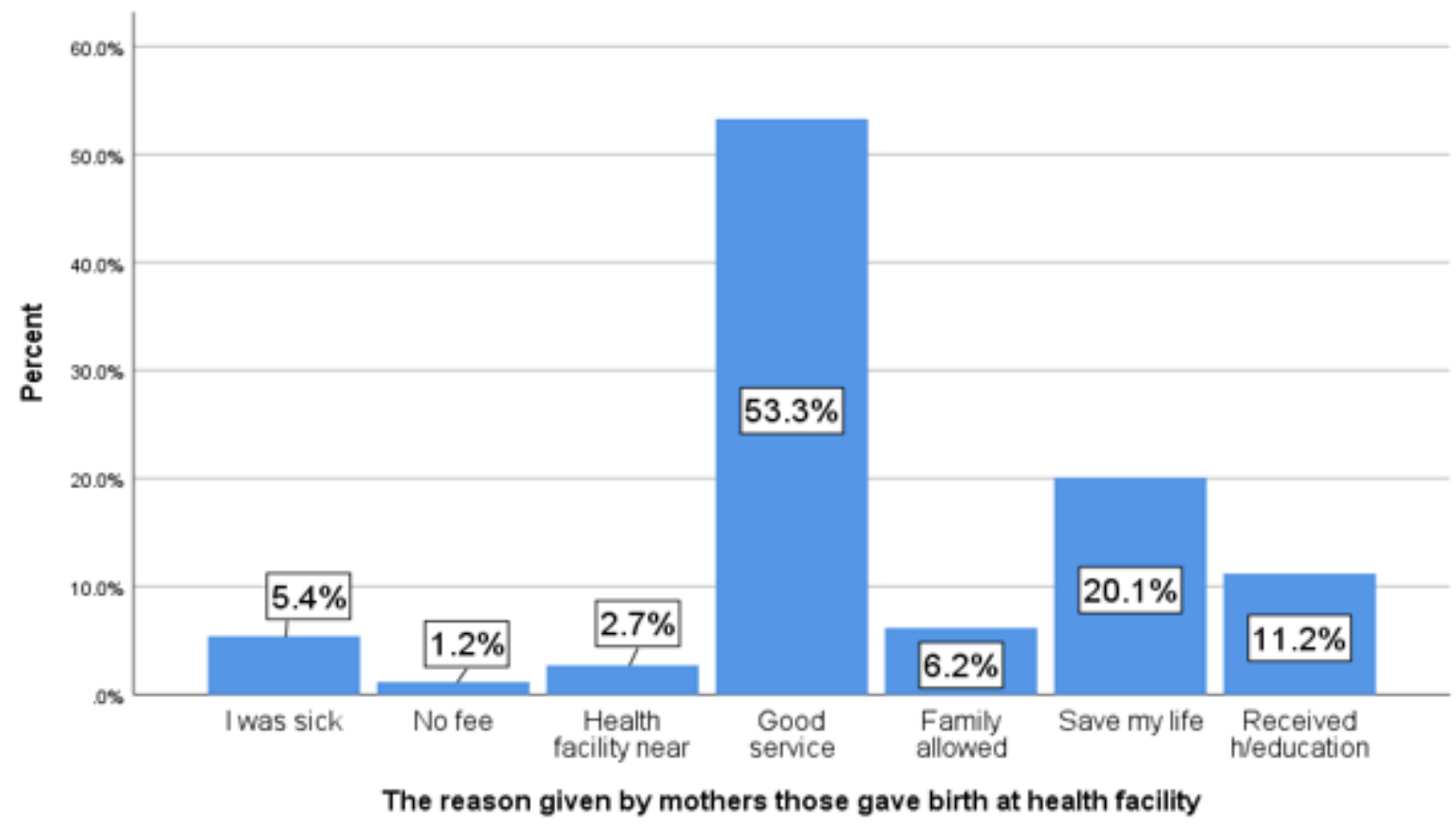

\section{Figure 3}

The reasons given by the mothers gave birth at health facility of women of childbearing age in Bule Hora town, West Guji Zone, Oromia regional state, Ethiopia, 2018.

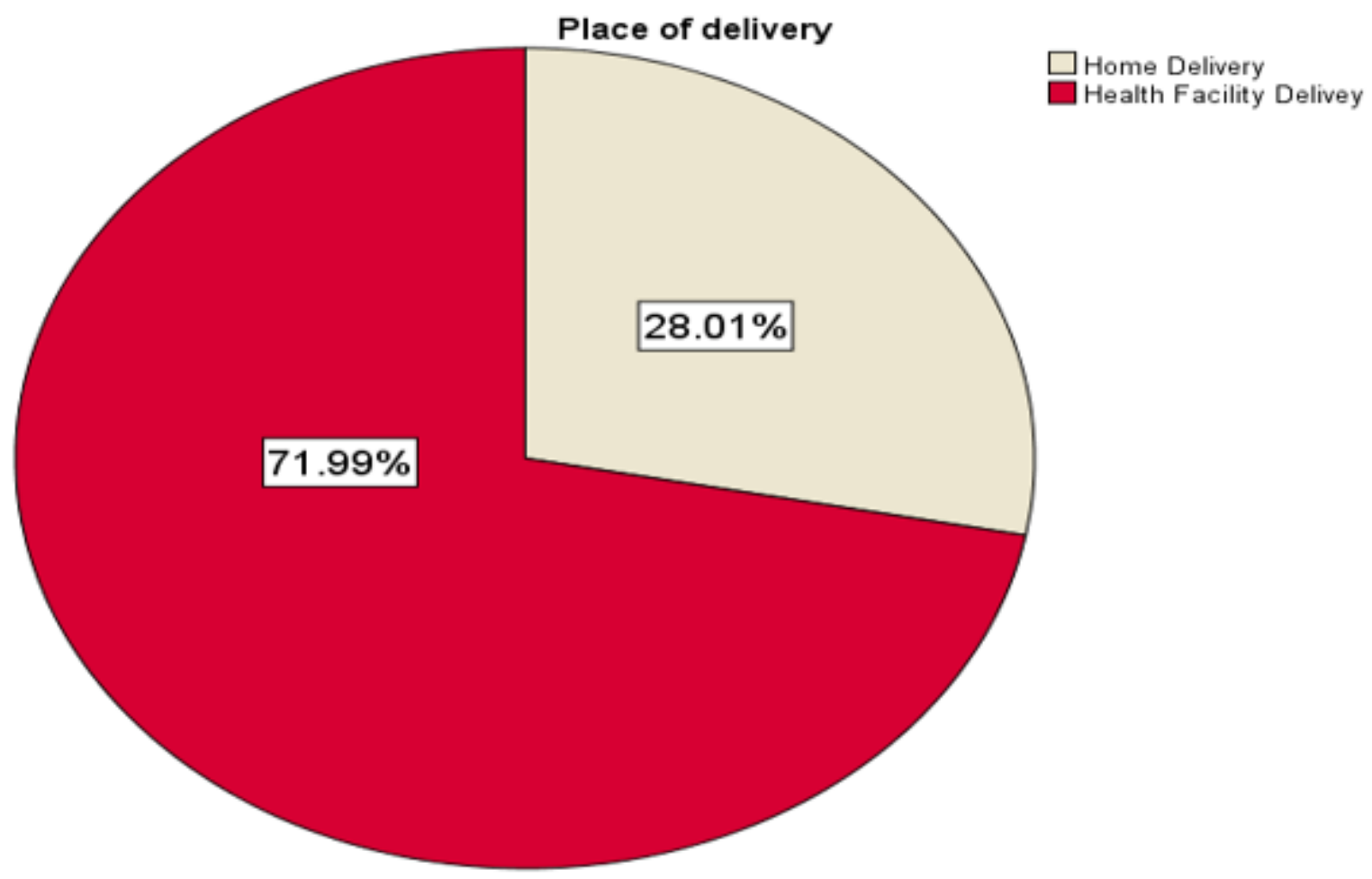

\section{Figure 4}

shows the utilization of institutional delivery service among women of childbearing age in Bule Hora town, West Guji Zone, Oromia regional state, Ethiopia, 2018. 


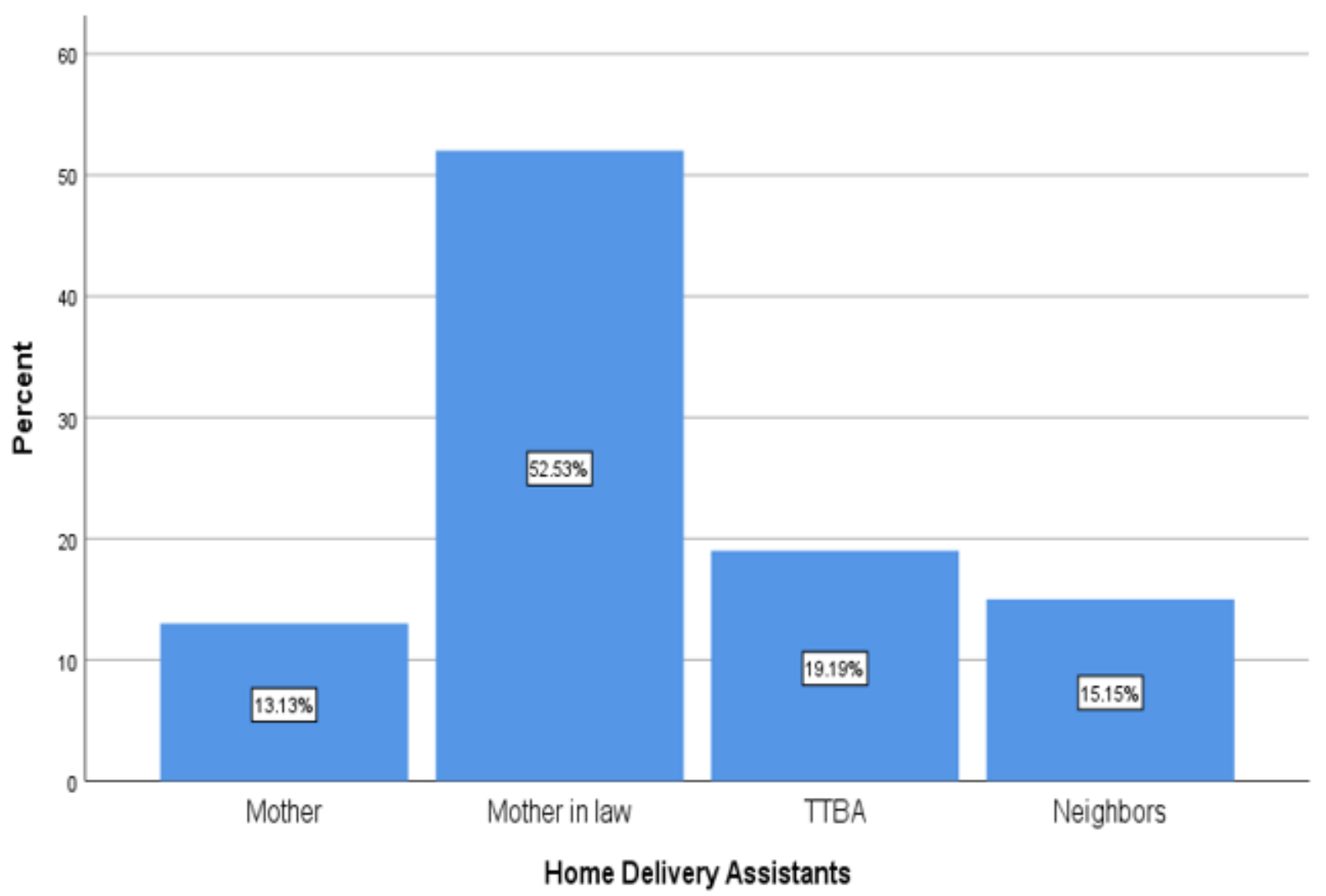

Figure 5

Shows who assisted mothers gave birth at home among women of childbearing age in Bule Hora town, West Guji Zone, Oromia regional state, Ethiopia, 2018.

\section{Supplementary Files}

This is a list of supplementary files associated with this preprint. Click to download.

- supplement1.pdf

- supplement2.pdf 